\title{
España entre el absolutismo y el liberalismo: Francisco Abad-Moreno Calvo. Un héroe por la libertad
}

\author{
Francisco Asensio Rubio
}

\section{LOS PRIMEROS AÑOS DE SU VIDA. LA GUERRA DE LA INDEPENDENCIA}

Francisco Abad-Moreno y Calvo había nacido el día 24 de abril de 1788 en la ciudad de Valdepeñas en cuya parroquia de la Asunción de Nuestra Señora fue bautizado el 1 de mayo de ese mismo año, con el nombre: Manuel Francisco Maria Gregorio. Era hijo legítimo de Francisco Abad-Moreno y de Josefa Calvo, ambos naturales de Valdepeñas. Vivió, al parecer, en el $n^{\circ} \mathbf{4 0}$ de la calle Ancha de la mencionada ciudad, en donde había nacido en 1788. De su aspecto físico sabemos que era alto, fuerte y moreno, según nos lo describe el historiador local. E. Vasco ${ }^{1}$.

Poco sabemos de sus años de niñez y de adolescencia, si sabemos que le tocó vivir los últimos años de finales del siglo XVIII y comienzos del $\mathrm{XIX}$, una etapa sacudida por profundos cambios sociales, políticos y culturales; no hay que olvidar que se inicia en Francia la Revolución, Europa cambia totalmente de fisonomía política y que España vive una profunda crisis política y social. Contaba en 1808 , en el momento en que estalla el motín de Aranjuez y se produce la participación de la masa en la vida política española, 20 años de edad.

De su actividad militar nos resulta fácil reconstruir sus pasos, ya que su Hoja de Servicios, aunque desapareció en un incendio ocurrido en la sección de Secretaría del Archivo Histórico Militar de Segovia la noche del 29 al 30 de noviembre de 1846, se ha conservado gracias a

1 Vasco, E. Guerra de la Independencia. Ocupación e incendio de Valdepeñas por las tropas francesas en 1808, Imprenta Mendoza, Valdepeñas, 1908. Pág. 45. 
que en 1814 Fernando VII mandó imprimir sus méritos en la Imprenta Nacional ${ }^{2}$.

La razón que impulsó a Abad a su entrada definitiva en la guerrilla parece ser que fue la muerte de su madre y hermano acontecida en plena Guerra de la Independencia, en 1808. Sin embargo, antes de formar su partida, Abad se distinguió como miembro de la de José Cacho y de la de José Villalobos, sin olvidar su participación en la lucha contra los franceses el 6 de junio de 1808, donde ya alcanzó una popularidad importante por su heroismo en la defensa de Valdepeñas. Su partida nació, según Vasco, el 20 de febrero 1810, teniendo como lugartenientes a sus paisanos Juan Bacas y Juan Toledo. Su grupo guerrillero se ubicó habitualmente en el paraje Cañada de los Frailes, en el propio término de Valdepeñas; su partida alcanzó, en estimaciones de Vasco, los 400 caballos. Su actividad como guerrillero fue grande, interviniendo activamente en 78 acciones de guerra, interceptando correos, convoyes, y aniquilando a «más de mil trescientos cincuenta franceses" ${ }^{3}$. Habria que afirmar con Aymes que, seguramente, el móvil de la entrada de Abad en la guerra no fue el exclusivamente familiar, como ocurrió en la mayoría de los otros guerrilleros, sino que obedecia también a otros factores; en palabras del historiador francés: "Ponerse a la cabeza de una partida es escalar de cuatro en cuatro los escalones jerárquicos; en caso extremo significa pasar en pocos meses de labrador a mariscal» ${ }^{4}$.

El caso es que Francisco Abad se convierte pronto en un cabecilla destacado de la resistencia española contra el francés, alcanzando gran popularidad. Fue conocido por Chaleco apodo que hace referencia a su modo de vestir, al igual que el de otros guerrilleros de la época -Caracol, Tres Pelos, el Manco, el Empecinado, Pastor, Capuchino, el Estudiante, etc.-, podía hacerlo a la procedencia social, rasgos físicos, etc.

De su actividad militar en la Guerra de la Independencia hay que decir que se encargó fundamentalmente de hostigar la comarca de Valdepeñas, de donde era natural y que, por ello, conocía en profundidad. Preferentemente atacó su propia villa natal, Santa Cruz de Mudela, Viso del Marqués, Venta de Cárdenas y los pueblos de Jaén que servían de prolongación a estas otras ciudades manchegas, dificultando las comunicaciones, el

VASCO, E. Valdepeñeros ilustres. Apuntes biográficos, Imprenta Castro Pérez, Valdepeñas, 1890-95. Págs. 27 a 73

VASCO, E. Guerra de..., op. cit., pág. 45.

Aymes, J.R. La Guerra de la Independencia en España (1808-1814), Ed. Siglo xx।, Madrid, 1975, pág. 38. 
abastecimiento y la defensa de Andalucía, la zona más difícil de conquistar y asimilar para el ejército francés. Los golpes los asestaba Chaleco en emboscadas, cuando tenía la certeza de derrotar al enemigo, de donde, en caso adverso, podía huir con facilidad, aprovechando el conocimiento del terreno. En definitiva, puso en práctica la teoría de las guerrillas y ello causó bastantes problemas al ejército francés en este paso-llave de Sierra Morena.

Sus actuaciones militares no se centraron sólo en la zona de Valdepeñas, sino que se realizaron, a veces, en la parte este de la provincia de Ciudad Real y en la zona colindante de la provincia de Albacete. En este sentido, Chaleco impidió la conexión de la ayuda militar francesa desde Levante a Andalucía.

En ocasiones, sus batidas llegaron hasta Jaén y Córdoba, aprovechando las ventajas geográficas que le daba la zona de Sierra Morena. En general, si examinamos las actuaciones militares de nuestro guerrillero, observamos que casi siempre sus acciones se dan cerca de zonas geográficas inhóspitas, sierras del sur y este de la provincia de Ciudad Real.

A finales de 1812 Chaleco comienza a realizar incursiones en Jaén y Córdoba y llega a Toledo y Madrid, una vez que la Guerra de la Independencia va consolidándose del lado español y sus fuerzas se suman al ejército oficial español. En 1812, en plena Guerra de la Independencia, Francisco Abad integra su partida de guerrilleros con el ejército mandado por el general Francisco Javier Elio, con la condición de ser reconocido como Coronel de Caballería y sus guerrilleros como regimiento oficial de la Regencia. La Regencia aceptó la integración y el cargo ofrecido por Elio a Francisco Abad. Se creó así el Regimiento de Cazadores de la Mancha capitaneado por el Coronel Abad. De todo esto habria que deducir que Chaleco formó parte de la resistencia cerca de tres años, desde febrero de 1810 a diciembre de 1812, fecha en que se integró su partida en la del general Elio y en la que se le reconoce el cargo y sueldo dentro del ejército, aunque su funcionamiento como regimiento siguió participando de la táctica y de la organización típica de la guerrilla de los años anteriores ${ }^{5}$. Esta integración, más nominal que real, de Francisco Abad en el ejército regular no nos debe extrañar ya que, pasado el primer momento de la guerra y organizada la resistencia, las autoridades centrales, a las que les producía horror la anarquía, intentaron institucionalizar las guerrillas. Como afirma

\footnotetext{
Francisco Abad pasó a Coronel por orden de la Regencia de fecha 27 de septiembre de 1812, y su regimiento quedó adscrito al $2^{\circ}$ ejército mandado por el General Elio. Con posterioridad, el 23 de octubre de 1814, Fernando VII revalidó su cargo de Coronel a Francisco Abad.
} 
Aymes: "La guerrilla, fenómeno esporádico al principio, se trasforma luego en fenómeno de masas. La estructura sustituye a lo informe" 6 .

De la capacidad humana de Chaleco apenas se ha dicho nada, pero hay que resaltar que Abad fue, a la par que un ejemplar guerrillero y militar, un excelente defensor de lo que hoy llamamos derechos humanos.

Buena prueba de ello es lo que ocurre en marzo de 1812. El Comandante de la plaza de Consuegra le envía una carta donde le pide que trate bien a los oficiales que ha apresado Abad de su guarnición. Éste le contestó afirmando que ya tenía experiencia en el trato de los prisioneros, y que por esto, siempre había mirado con "desprecio" la "ferocidad francesa" para con los prisioneros españoles, a los que fusilaban sin compasión. Chaleco le comunicó que no tuviera cuidado, que no tomaría represalias contra los oficiales apresados: "Todo esto, Señor, representaba en la ocasion de poder tomar satisfacion, pero lexos de hacerlo en debida correspondencia, los he mirado aun con mas humanidad que me previenen las sabias leyes de la guerra, y que se guardar. Todos debian morir por su obstinacion en no entregar las armas, procurando muchos de ellos ofender á los mismos que les acababan de conceder la vida; $y$ en medio de todo esto, los perdono y consuelo en su muerte: llevo en mis propios caballos á quantos no podian marchar y últimamente son socoridos en sus heridas, antes que mis valientes soldados" ?.

La figura de Abad despertó, ya en plena Guerra de la Independencia, una admiración especial entre los valdepeñeros, aunque luego algunos, unos años más tarde, se mostraran partidarios de su ejecución. En septiembre de 1812 Francisco Abad llegó a Valdepeñas, liberada en estas fechas del ejército francés, en medio de un profundo clamor popular, como nos lo revela la prensa de la época. "Esta tarde han llegado á esta villa los esquadrones francos de su nombre mandados por su valiente Gefe Don Francisco Abad Moreno (Chaleco), siendo universal el gozo al ver marchar a reunirse el exército segundo y tercero..." ${ }^{8}$.

Sabemos, por lo que nos ha sido relatado por Eusebio Vasco, que desde el principio de la formación de su partida Chaleco contó con dos fieles valdepeñeros, Juan Toledo y Juan Bacas; sin embargo, sabemos poco sobre éstos y sobre los oficiales que componían, también, la partida de

AYMES, J.R. op. cit., pág. 57

Gaceta de la Junta Superior de la Mancha. Elche de la Sierra. 11 abril 1812.

Gaceta de la Junta Superior de la Mancha. Elche de la Sierra. 21 septiembre de 1812. 
Abad. Hay que destacar, entre éstos, a Eugenio Sánchez (Teniente), Juan Navalón (Capitán), Vicente Abad (Capitán), Juan Regayón (Capitán), Pedro González (Alférez).

Para el historiador francés Aymes la expansión demográfica que afectó al siglo XVIII fue el caldo de cultivo de las guerrillas de 1808, agravada esta situación por el alto paro masculino existente. En el caso de los lugartenientes de Francisco Abad eran de procedencia humilde, esencialmente campesinos o pequeños propietarios. A excepción de Juan Navalón, de origen nobiliario, el resto aparecen en las hojas de servicio como honrados, es decir del estado llano. Las razones que los impulsaron a integrar la partida de Chaleco y su enrole en el ejército guarda estrecha relación con la defensa del ideal patriótico, con el espíritu de aventura en algunos casos, o con la manera de superar la marginación social, dado que la guerra era una fórmula de redimir el origen social, en otros.

De entre los nombres citados como ayudantes de Francisco AbadMoreno cabe destacar, fundamentalmente, a Juan Toledo y Juan Bacas. Alistados ambos, junto con Chaleco, como soldados voluntarios el 1 de marzo de 1809, pronto se distinguieron por su valor y capacidad militar. En 1810 eran los hombres de confianza de Abad y años más tarde se convertirian en oficiales del regimiento de Chaleco.

Juan Toledo había nacido en Valdepeñas en 1791, algo más joven que Abad, y contaba 18 años cuando ingresó como voluntario en los Cuerpos Francos. De profesión propietario-agricultor, como él confesaría a Fernando VII años más tarde, se presentó voluntario «impulsado - dice él- de los mas ardientes deseos en defender los sagrados derechos de V.M. y la Santa religión que profesamos, ultrajada por el intruso Napoleon". Juan Toledo se había incorporado a filas con "cavallo y equipo propios" pasando a la partida de Abad y posteriormente al Regimiento de Cazadores de la Mancha.

Pronto, por sus muchos méritos militares y acciones de guerra, Juan Toledo fue elevado al grado de Subteniente de Infantería en septiembre de 1810, mediante concesión de la Regencia y por título expedido por el general Castaños. En junio de 1811 alcanzaba el grado de Capitán de Infantería en el regimiento de Abad. Al terminar la Guerra de la Independencia, Juan Toledo fue ascendido por el rey Fernando VII al empleo de Comandante, pero, reincorporado el ejército regular, lo hizo con el grado de Capitán, sirviendo, sucesivamente, en el Regimiento Caballería del Príncipe y en el de Borbón. 
Implicado, como su amigo y compañero Chaleco, en la defensa del orden liberal y constitucional en los años del Trienio, fue destinado a la guarnición de Moral de Calatrava; en 1822 fue retirado forzosamente por su actitud liberal y se rehabilitó en 1824 incorporándose al ejército con el grado de Capitán. Destinado con posterioridad a Aragón y «purificado... de la conducta militar - reza la Hoja de Servicios- y política observada durante el Gobierno Constitucional", ascendió a Primer Ayudante en 1826. En 1830 obtenia la cruz de la Real y Militar Orden de San Hermenegildo.

Terminada la Década Ominosa, con la muerte de Fernando VII, pronto se distinguió como militar liberal en las guerras carlistas, sirviendo a las órdenes, como Ayudante de Campo, del ciudarrealeño D. Baldomero Espartero desde octubre de 1834 a finales de 1838. Por su participación y heroísmo en el levantamiento del cerco de Bilbao le fue concedido por el general Espartero, "sobre el campo de Batalla", el empleo de Teniente Coronel en 1836 y un año más tarde alcanzaba el grado de Coronel Mayor. En 1839 fue destinado a Cataluña con el objeto de combatir a las partidas carlistas de la zona y fue ascendido a Brigadier. Siendo Regente de España D. Baldomero Espartero, se le concedió, en 1841, el empleo de Mariscal de Campo ${ }^{9}$.

Juan Bacas también compañero en la partida de Chaleco, no tuvo una vida militar tan dilatada; su historial militar se reduce sólo a la Guerra de la Independencia. Natural de Valdepeñas, en donde había nacido en 1784 , ingresó en el ejército como soldado voluntario el 1 de marzo de 1809. En 1810 estaba en la partida de Francisco Abad por lo que intervino activamente en las acciones dirigidas por éste, destacando por sus dotes militares y alcanzando el grado de Teniente de Infantería en julio de 1810; en junio de 1811 recibió el despacho de Sargento Mayor del general Castaños. Al terminar la guerra siguió en activo, adscrito al Regimiento Pavía $n^{\circ} 4$ de Ligeros, hasta que en 1819 el rey le concedió el retiro como Alférez en la ciudad de Barcelona. En diciembre de 1820, y gracias a la solicitud de Abad al rey, le fue reconocido el grado de Comandante en calidad de retirado en Valdepeñas ${ }^{10}$.

Del Teniente $D$. Juan Navalón sabemos que era natural de Casas Ibáñez, que era noble y que había nacido en 1789. Juan Navalón se había

\footnotetext{
9 Expediente Personal y Hoja de Servicios del Mariscal D. Juan Toledo. Archivo Histórico Militar de Segovia.

${ }_{10}$ Expediente Personal y Hoja de Servicios del Comandante D. Juan Bacas. Archivo Histórico Militar de Segovia.
} 
alistado en el ejército como soldado voluntario en enero de 1802 y era Cabo Segundo cuando se inició la Guerra de la Independencia. Siendo soldado del Regimiento de Caballería de Alcántara participó en el sitio de Gibraltar y en la campaña de Portugal de 1808; hecho prisionero en dicha campaña, consiguió fugarse del castillo de San Juan de la Barra. Después de intervenir activamente en acciones militares diversas en Extremadura, fue destinado en 1810 al regimiento dirigido por Francisco Abad, en donde permaneció hasta el final de la guerra. En 1812 alcanzó el empleo de Teniente, y en 1821 el rey le concedió el retiro en su ciudad natal, Casas Ibáñez ${ }^{11}$.

Finalmente Eugenio Sánchez era también, natural de Valdepeñas en donde había nacido en 1780 . Se enroló al ejército como voluntario en diciembre de 1808 y recibió instrucción hasta 1809 . Soldado de Infantería en el Regimiento de Barbastro, fue destinado en 1810 al regimiento de Francisco Abad; en dicho regimiento permaneció hasta finales de la contienda, alcanzando el grado de Capitán. Posteriormente pasó al Regimiento del Príncipe y al de Montesa con el mismo grado; el rey le concedió el retiro en noviembre de 1819 con la paga y el grado de Teniente ${ }^{12}$.

\section{LOS PRIMEROS AÑOS DEL REINADO DE FERNANDO VII}

Concluida la Guerra de la Independencia, Francisco Abad es reconocido por el rey Fernando VII, el 23 de octubre de 1814, como Coronel del Regimiento de Caballería Escuadrones Francos Cazadores de la Mancha. Acorde con la nueva filosofía política, Fernando VII disuelve todas las partidas de guerrilleros que habían combatido en la Guerra de la Independencia, ya que la razón que las había creado, la guerra contra el francés, había desaparecido. El regimiento mandado por Chaleco no debía ser disuelto, ya que como antes hemos dicho, se había convertido por mandato de la Regencia en una parte más del ejército español; Fernando VII, sin embargo, disolvió el mencionado regimiento en 1814 y nuestro guerrillero protestó ante la administración fernandina por ello; Francisco Abad no obtuvo de ésta nada más que su reconocimiento como Coronel

\footnotetext{
"Expediente Personal y Hoja de Servicios del Teniente D. Juan Navalón. Archivo Histórico Militar de Segovia.

12 Expediente Personal y Hoja de Servicios del Teniente Agregado D. Eugenio Sánchez. Archivo Histórico Militar de Segovia.
} 
de Caballería, con un sueldo como los de la "línea». La negativa de Fernando VII a reconocer este regimiento como parte del ejército español de 1814, obedecía a que no estaban los expedientes originales en que constaba la decisión de la Regencia al respecto y tampoco se encontraba el informe que en su momento emitió el inspector General ${ }^{13}$.

El regreso de Fernando VII, mal apodado "El Deseado", supuso para España, y especialmente para los sectores más progresistas de la sociedad española, una vuelta atrás. Los defensores del absolutismo, entre los que destacaba el general Elio, y los partidarios del liberalismo y del orden constitucional, entre los que se encontraba Francisco Abad, preparaban el camino para esa nueva etapa política. Fernando VII respaldando al sector absolutista del ejército y de la sociedad española, tras el Manifiesto de los Persas, terminaba con las esperanzas liberales y se iniciaba esta primera etapa de su reinado caracterizada por la vuelta al absolutismo de la monarquía ilustrada dieciochesca.

A pesar de su juventud y de su vida azarosa, Francisco Abad habia contraído matrimonio con Antonia Frías y Torres, natural de Tembleque, y de este matrimonio había tenido dos hijas, Francisca y María AbadMoreno Frías. Su esposa falleció el 16 de marzo de 1814, recién acabada la Guerra de la Independencia, y sus dos hijas, que poseían corta edad, necesitaban de su atención. Francisco Abad, en 1814, solicita del rey permiso para retirarse de su vida militar, seguramente impulsado no sólo por sus circunstancias personales, sino por la situación política que vive el país. En 1814 el Coronel Abad vivió retirado en la localidad manchega de Tembleque, percibiendo un sueldo de mil reales de vellón al mes, a razón de doce pagas anuales — según había estipulado el rey-, con la obligatoriedad de presentarse a la Justicia de aquella localidad cada tres meses, al objeto de verificar su existencia. En 1815, con tan sólo 27 años de edad, Chaleco había vivido una guerra, habia enviudado y era padre de dos hijas; estas experiencias determinarán su posición posterior y le convertirán en uno de los hombres más importantes de la época en nuestra provincia.

En 1815 Francisco Abad dirige una instancia al rey con el objeto de obtener permiso para contraer matrimonio en segundas nupcias con Sacramento Muñoz y Castro, vecina y natural de Valdepeñas, de estado soltera, honrada y noble (poseía titulo de hidalguía), de dieciséis años

13 Expediente Personal y Hoja de Servicios de Francisco Abad-Moreno Calvo. Archivo Histórico Militar de Segovia. Documentación manuscrita de la época. 
edad. Tras tener que remitir al rey múltiple documentación -certificado de su partida de nacimiento, certificado de la partida bautismal de su segunda esposa, certificado de defunción de su primera mujer, certificado de compromiso matrimonial entre María del Sacramento Muñoz y Francisco Abad, certificado de hidalguía de su segunda esposa, copia certificada del expediente y despacho por el que Fernando VII concede a Abad el grado de Coronel retirado, etc.-, obtuvo permiso para verificar su matrimonio, y éste se celebró en Valdepeñas el 2 de junio de $1815^{14}$.

Francisco Abad en 1820 solicita para sus antiguos oficiales los grados que habían tenido en la Guerra de la Independencia, así como los sueldos correspondientes a los mismos. El rey contestó favorablemente a la petición de Abad, y siete oficiales del mencionado Regimiento de Cazadores de la Mancha fueron considerados como oficiales del ejército y no como oficiales "de cuerpos francos", aunque el rey no les reconoció haber alguno, a pesar de ser oficiales. Abad insistió de nuevo ante la administración fernandina para conseguir el reconocimiento de un sueldo para sus antiguos leales; finalmente Fernando VII resuelve el pleito, reconociendo la paga de haberes a los mencionados oficiales, que percibirian asi el sueldo de un grado inferior al que poseian ${ }^{15}$.

De los años que van de 1814 a 1820 poco sabemos sobre la vida de Chaleco. En 1815, tras su segundo matrimonio, debió fijar su residencia en su ciudad natal, Valdepeñas, por lo que se deduce de su correspondencia. Esta etapa de la historia de España estuvo sacudida por profundas convulsiones políticas derivadas del enfrentamiento entre absolutistas y liberales constitucionalistas. Su vinculación desde el principio al liberalismo va a ser evidente, pero, desgraciadamente, poseemos poca información sobre estas actividades de Abad en este período, ya que tradicionalmente ha interesado más a los historiadores y eruditos de esta figura los hechos relacionados con la Guerra de la Independencia que los hechos posteriores a esta, siendo incluso los últimos tan interesantes como los anteriores.

Los años anteriores a 1820 habían estado salpicados de pronunciamientos liberales ante la política conservadora y absolutista de Fernando VIl; asi lo habían intentado Espoz y Mina, Porlier, Lacy, Milans del Boch,

\footnotetext{
${ }_{14}$ Expediente Personal y Hoja de Servicios de Francisco Abad-Moreno Calvo. Instancia dirigida al rey para contraer matrimonio en segundas nupcias. Archivo Histórico Militar de Segovia.

15 Expediente Personal y Hoja de Servicios de Francisco Abad-Moreno Calvo. Archivo Histórico Militar de Segovia.
} 
Vidal, etc., sin conseguirlo. Ahora, tras múltiples intentonas, Riego conseguía proclamar en Cabezas de San Juan (Sevilla) la Constitución gaditana, al mismo tiempo que establecía las primeras instituciones liberales. Estaba claro que la revolución fracasaría si ésta no se extendía al resto de las provincias españolas. Lentamente las grandes ciudades andaluzas se fueron sumando al levantamiento liberal, al igual que otras de fuera de la región: La Coruña, Zaragoza, Barcelona, Pamplona, Murcia y Madrid. Para los sublevados el levantamiento de Madrid era fundamental, ya que era el centro neurálgico del país, y además su capital, pero a punto estuvo de malograrse, dado que nuestro guerrillero valdepeñero, implicado en él, fue descubierto con otros cabecillas, la madrugada del 3 de marzo. Detenido y conducido al cuartel del Pósito y desde allí trasladado a Valladolid, no fue decapitado y salvó su vida porque los estudiantes de la Universidad, ya vinculados al liberalismo, lo liberaron. Proclamada la Constitución gaditana en Valladolid, fue "aclamado y paseado por las calles de aquella ciudad" ${ }^{16}$, concediéndosele el reingreso en el ejército con el grado de Brigadier.

Proclamada la Constitución de 1812, aceptada por el rey Fernando VII, y aprobados los primeros decretos reformistas (supresión de la Inquisición, celebración de elecciones, formación del primer gabinete liberal, inicio de la desamortización, etc), los liberales pronto quedarán divididos en dos grandes ramas: los moderados, partidarios de una revolución liberal limitada, y los exaltados, partidarios de una revolución radical. Los enfrentamientos entre unos y otros debilitarán los gabinetes liberales y favorecerán la aparición de grupos extremistas por la izquierda y la derecha (absolutista y comuneros).

En 1821 los Guardias de Corps intentaban dar un golpe de estado en Madrid, que acaba fracasando por la aparición de una guerrilla urbana. Estos hechos provocan una crisis de gobierno y dan lugar a la formación de un segundo gabinete liberal, más moderado que el anterior. Las protestas crecientes y el intento de designar autoridades populares para cargos políticos, provocan una segunda crisis de gobierno, saldada con otro nuevo gabinete. 1822 fue un año en que la contrarrevolución va consolidándose y los sucesos de Aranjuez, Valencia, Navarra, Cataluña, Murcia y Madrid lo demuestran palpablemente.

Los acontecimientos de Madrid, sin duda los más graves de todo el Trienio, ponen de manifiesto el enfrentamiento latente en la sociedad

${ }^{16} V_{A S C O}$ E. Guerra de..., op. cit., pag. 46. 
española. La Guardia Real, apoyada por el rey, la aristocracia y el propio Gobierno asaltan el Pardo e intentan tomar Madrid. La Milicia Nacional Voluntaria y el Batallón Sagrado resisten el asalto y derrotan a los contrarrevolucionarios. Los conservadores acuden a la Santa Alianza, con la finalidad de acabar con la Constitución de 1812 y con la experiencia liberal española. En septiembre de 1823 Fernando VII, tras la entrada en España de los Cien Mil Hijos de San Luis, era proclamado monarca absoluto. La revolución liberal tendría que esperar algunos años más.

Durante este periodo nuestro valdepeñero ilustre había alcanzado el grado de Brigadier y había sido nombrado Comandante General de la Mancha, cargo que ocupará hasta el 26 de octubre de 1823, fecha en la que Fernando VII ordena su traslado, ante su te en el liberalismo y la Constitución gaditana, a la guarnición de Palencia, junto con su amigo José Selles, que fue trasladado a Almazán.

\section{LOS ÚLTIMOS AÑOS DE SU VIDA. LOS COMUNEROS DE VALDEPENAS}

La represión brutal que se inicia en 1823, tras la restauración absolutista de Fernando VII, va a conducir a los liberales al exilio, la cárcel o el cadalso, como únicas alternativas. El 7 de noviembre de 1823 era ejecutado Riego, símbolo donde los haya de la libertad y el orden constitucional, y ese mismo día decretaba Fernando VII que se procediera al arresto del Coronel Francisco Abad-Moreno por "crimenes que no fueron comprendidos en la capitulacion concluida entre el y las tropas de S.M. Cma." ${ }^{17}$.

Contrariamente a como dice Vasco, Chaleco no fue detenido en Almedina, ni descansaba en Albaladejo, por lo que se deduce de la documentación del Archivo Histórico Militar de Segovia. Francisco Abad debió intuir a finales de octubre que lo detendrían y desapareció. Se ordenó, entonces, a las autoridades de Manzanares, pensando que el mencionado Abad pasaria por aquella ciudad, que fuera detenido. Las autoridades de esta localidad no pudieron detenerlo, ya que la orden que se les habia dado era de fecha posterior al paso de Chaleco por la citada ciudad. Finalmente el 24 de noviembre de 1823, y no el 20 de diciembre como afirma Vasco, fue comunicado al rey por su Secretario de Despacho de Guerra la detención del coronel Abad, quien para mayor seguridad fue

17 Documentación manuscrita de la causa tormada a Francisco Abad, en ella consta la techa de la detención, acusación y cargos contra él. Archivo Histórico Militar de Segovia. 
Ilevado a la cárcel de Consuegra, desde donde luego se le trasladaría a Valdepeñas, a petición del alcalde mayor de la ciudad, Víctor Lorente, quien lo reclama al rey alegando que se estaba «siguiendo causa por los crimenes de que resulta culpado".

El Secretario de Despacho de Guerra dispone, previa consulta con el rey, que Francisco Abad sea puesto a disposición del alcalde de Valdepeñas, para que sea juzgado allí, en su villa natal; así mismo dispuso que, para el traslado del reo y otros seguidores suyos, se le "facilite el auxilio de cien soldados del Batallon de Infanteria de la reyna Amalia para la custodia de aquel y demas presos existentes en las reales Carzeles de otro punto" ${ }^{18}$. Fernando VII aceptó la entrega del Coronel Abad a la Justicia de Valdepeñas, pero pidió con insistencia al mencionado Secretario que se le tuviese puntualmente informado del "delito de que Abad es acusado y estado de la causa que consta el que se sigue en su Juzgado".

Con fecha 12 de diciembre de 1823 la Justicia de Valdepeñas acusa a Francisco Abad-Moreno de "revelion y conspiracion directa" como jefe de la Comunidad de la provincia "vajo el nombre de Castellano con las armas en la mano, y de acuerdo con los de las otras del Reyno llamadas Merindades la Soverania del Pueblo, ó lo que es lo mismo el articulo tercero de la llamada Constitucion politica de la Monarquia, pribar al Soberano Rey y Señor natural reinante Don. Fernando Septimo que Dios guarde, de los impresciptibles derechos de su lexitima soberania, excitar la anarquia y Guerra Civil, persiguiendo de muerte a todos los amantes del Rey, hasta conseguir no solo que subsistiese la forma de govierno que la rebelion de las armas habia entronizado, si también establecerla a su modo jurando imitar las virtudes de los revolucionarios de nuestra Histora Padilla, Lanuza, Bravo, y Maldonado, Comuneros de Castilla, á quienes llamaban Heroes y morir en defensa de sus fueros..." 19.

Las Comunidades eran sociedades secretas inspiradas en el modelo carbonario italiano, y algo en la Masonería francesa, que perseguían intervenir activamente en la sociedad, particularmente en la vida política española. Habian florecido con intensidad durante el Trienio Liberal, al amparo de la libertad de este corto período histórico, y se mostraban defensoras a ultranza de la libertad y del modelo constitucional gaditano.

\footnotetext{
is Documentación manuscrita inserta en el expediente personal de Francisco Abad. Archivo Histórico Militar de Segovia.

is Expediente Personal de Francisco Abad. Resumen de la acusación existente en dicho expediente Manuscrito 1822/23. Archivo Histórico Militar de Segovia.
} 
En otro sentido, las Comunidades habían surgido en ese período para protestar contra el modelo de liberalismo defendido por los moderados y la monarquia. Están consideradas como una versión a la española de la Masonería francesa, a la que estos estimaban como de reaccionaria. La palabra Comunidades estaba retomada de los hechos históricos españoles que llevaron a los castellanos a enfrentarse con el rey Carlos $V$ a comienzos de la Edad Moderna, y de los enfrentamientos que se produjeron entre los aragoneses y Felipe II por la cuestión de Antonio Pérez. Tampoco nos puede extrañar la elección de este modelo simbólico por los liberales españoles, en principio porque es necesario en toda revolución la elección de símbolos, y en segundo lugar porque las Cortes mismas en 1822, con Riego a la cabeza, habían decretado elementos beneméritos de la patria a Juan Bravo, Padilla, Maldonado y a los aragoneses Juan de Lanuza, Diego de Heredia y Juan de Luna. Para los liberales decimonónicos como Francisco Abad vinculados, a las Comunidades, esta referencia histórica tenía una clara significación en la sociedad de ese momento: la resistencia, como los hicieron los Comuneros y aragoneses, al poder absoluto y omnímodo del rey, en este caso Fernando VII.

La aparición de este movimiento comunero, según determinados autores, se produjo a principios de 1820, como consecuencia de la escisión provocada en la francmasonería española; dicho sector coincidiría políticamente con el sector más radical del liberalismo español, disconforme, por tanto, con la política de los liberales moderados de la primera fase del Trienio Liberal. Entre los comuneros más significativos de estos primeros momentos cabe destacar a Romero Alpuente, Flórez Estrada, Gutiérrez Acosta, Mejía, Riego, Mina, etc.

Al individuo que ingresaba en la sociedad comunera se le cubría, en ceremonia secreta, con el escudo de Padilla y el resto de los miembros comuneros posaban sus espadas sobre el escudo del iniciado, jurándose los principios de la secta. Los comuneros utilizaban como distintivo una banda morada, basándose en el color del pendón de los comuneros castellanos del siglo xvı.

La Torre era simplemente la reunión de la comunidad a nivel local, que reconocía como entidad superior la Asamblea Provincial (Junta Gubernativa), presidida por un jefe al que se le denominaba en clave secreta "Gran Castellano" o "Castellano". La Torre era una sección de la Merindad, su número no podía exceder de 50 miembros, y el mínimo para formarla era de 7.

La organización comunera era jerárquica, por ello sli representación en Madrid era "La Gran Asamblea", la cual estaba en correspondencia 
con los organismos provinciales o Merindades; el jefe de la "Gran Asamblea" o "Gran Castellano" trasmitía las órdenes a los jefes de las Merindades provinciales y éstos, a su vez, a las Torres y Casas Fuertes.

Las Merindades tenían su número de orden en función de su antigüedad, así en 1822 existian 50 en todo el país ${ }^{20}$, la de Ciudad Real, ubicada en Valdepeñas, ocupaba el n9, entre la de Valencia y León. Por ello la correspondencia que los comuneros del resto del país dirigen a Chaleco va a nombre del Castellano $n^{\circ} 9$, número de orden de la Torre de la provincia en clave.

Contaban con varios periódicos como órganos de expresión escrita, entre los más importantes cabe destacarse: "El Zurriago", "La Tercerola", "El Eco de Padilla», "El Patriota», "El Diario Constitucional», etc.

Tras las Jornadas de Julio los comuneros se dividieron en dos bloques. Esta división se produjo, por la petición de un sector de la comunería de buscar alianzas con los masones. El cabecilla de esta tendencia era Juan Palarea, delator ante el rey e infiltrado en estas sociedades comuneras, quien creó la facción denominada Comuneros españoles constitucionalistas, mientras los seguidores de la comunería tradicional se denominaron ahora Comuneros españoles; la división fragmentó el movimiento y les llevó a luchas fraticidas así como a su extinción, al tiempo que fenecía el Trienio Liberal.

De la Comunidad o Merindad de Ciudad Real, ubicada en Valdepeñas y presidida por Francisco Abad, se conservan extractos de su correspondencia, mediante la que luego se le acusará, y algunas circulares pertenecientes a la misma sociedad. La Comunidad de Valdepeñas se fundó,

20 FUENTE, Vicente de la. Historia de las sociedades secretas antiguas y modernas en España y especialmente de la Franc-masoneria, Imprenta Soto Freire, Lugo, 1870. En dicho libro, ya clásıco sobre el tema, se recoge una relación de Merindades comuneras existentes en España en 1822, hechas públicas por los propios periódicos comuneros; la relación es la siguiente:

1. Madrid; 2. Segovia; 3. Murcia*; 4. Jaén*; 5. Córdoba; 6. Valladolid; 7. Barcelona*; 8. Valencia; 9. Ciudad Real; 10. León *; 11. Zamora; 12. Ferrol; 13. Zaragoza; 14. Sevilla; 15. Tarragona*; 16. Badajoz; 17. Coruña; 18. Málaga*; 19. Granada*; 20 Logroño*; 21. Soria; 22. Cuenca; 23. Salamanca; 24. Burgos; 25. Cartagena; 26. Almeria; 27. Cádiz; 28. Oviedo; 29. Albacete; 30. Gerona; 31. Toledo. 32. Ávila; 33. Lugo; 34. Vitoria; 35 . Truel; 36. Plasencia; 37. ; 38. Palma de Mallorca*; 39. Palencia; 40. Santander; 41. Alicante; 42. Calatayud; 43. Tudela; 44. Guadalajara*; 45. Castellón*; 46. Lérida; 47. Huelva; 48. Bierzo; 49. Jávita.

Las ciudades que aparecen con un asterisco pertenecen a la corriente renovada del movimiento comunero, conocida con el nombre de Comuneros Españoles Constitucionalistas. 
por lo que se deduce de la correspondencia, a finales de 1821 , posiblemente como consecuencia de condiciones políticas adversas en la capital de la provincia, pero en 1823 se trasladará a Ciudad Real.

La estructura orgánica de la Merindad de Valdepeñas era la siguiente: el Castillo o Torre y la Junta Gubernativa. El primero lo componían todos los miembros comuneros de la localidad, y la segunda sólo algunos de los elementos de la Torre. El sistema de acceso debía ser restringido y el comunero debía pagar al ingresar una cantidad en metálico, en concepto de "patente y distintivo". La Justicia de Valdepeñas conoció la existencia de esta organización en 1823, una vez que prácticamente había desaparecido en esa ciudad, como consecuencia de hallar en la casa de Francisco Abad la mencionada correspondencia. Con posterioridad se descubrió y detuvo al presbítero Francisco Díaz Araque, natural de Valdepeñas, a quien también se le incautó parte de la correspondencia de la Comunidad de Valdepeñas y de otras de la provincia. Como fuera interrogado el presbitero y en la documentación mencionada aparecieran las rúbricas de otras personas de la Merindad de Valdepeñas, éstos fueron acusados y detenidos en la mayoría de los casos, días después.

Componian la Junta Gubernativa de la Merindad de Valdepeñas: Francisco Abad, quien era denominado con el nombre en clave de "Castellano no 9"; José María Pozuelo con el de "Vice Castellano"; José Corte Sánchez como secretario; Francisco Díaz Araque como tesorero; y como procuradores de las "Torres de la Provincia", especie de relaciones públicas con otras comunidades provinciales, Dionisio Pozuelo, Manuel de Jesús Recuero, Miguel Arroyo, Luis Baldelomar y Juan Martínez. Eran vocales de la Junta o simples comuneros: Rafael Córdoba, José Marquez, Antonio Bernalte Bueno, Antonio Moraleja, Manuel Bezares, Pedro Corrales, Antonio Merlo Marín, Mariano Cerrojo, Vicente Ambroz y José Garcia. Todos fueron detenidos, menos Baldelomar, Márquez y García; Moraleja fue apresado en Sevilla, en donde se le tomó declaración. Todos confesaron que la Comunidad de Valdepeñas fue fundada a comienzos del Trienio Liberal, "en tiempo del Govierno revolucionario" que dicen ellos, y que el "Castellano" y responsables de la Comunidad era Francisco Abad; los detenidos aceptaron que ocupaban los cargos más arriba relatados.

De esta documentación se deduce también que estas organizaciones se habían extendido entre los pueblos de la provincia; así existian sociedades comuneras en Almagro, Manzanares y La Solana.

Como la correspondencia que se les encuentra a Francisco Abad y a Francisco Díaz Araque no es la que la Justicia extracta en su totalidad, 
sino sólo parte, en la actualidad hemos perdido una porción importante de la información que ésta debía dar, tanto de la Comunidad de Valdepeñas como de las del resto del país. A pesar de esto, por la documentación que se conserva, sabemos que Francisco Abad fue nombrado Comandante General del Departamento de la Mancha en 1822, que ese año estuvo en Madrid en los Sucesos de julio, por los que los Guardias del Rey, con el apoyo del monarca, la aristocracia y el gobierno, intentaron dar un golpe de estado en favor del absolutismo. Estos sucesos provocaron en los sectores radicales del país, y entre los Comuneros también, una radicalización creciente, razón por la cual estos sectores pedian abiertamente la democratización de la sociedad. En estas jornadas estuvo Chaleco, quien informó, con posterioridad, a sus compañeros comuneros de Valdepeñas; también facilitó información a sus correligionarios comuneros del levantamiento absolutista ocurrido en Valencia, por el cual el general Elío -antiguo compañero de Abad en la Guerra de la Independencia-, a pesar de estar en la cárcel, fue acusado del delito de rebelión y condenado a garrote vil.

La Comunidad de Valdepeñas permaneció perfectamente informada de los acontecimientos políticos del resto de España durante el Trienio Liberal. En la correspondencia se informa del estado de la "causa" en Cádiz, Valencia, Madrid, Tembleque, La Roda, Vinaroz, Manzanares, etc. En esta documentación, interesantísima, se habla de las relaciones con otras comunidades, de la captación de individuos comuneros, de las perspectivas electorales, de los acontecimientos políticos o militares de última hora - derrota del Locho-, de los mecanismos y estrategias de presión popular, de cuestiones de orden interno, etc.

La Merindad de Valdepeñas fue trasladada en febrero de 1823 a Ciudad Real, informaba Francisco Abad al resto de las comunidades, como consecuencia de "haber ya cesado las causas que, en otro tiempo motivaron el establecimieno de la J.G. en este Pueblo" ${ }^{21}$, y a petición de los Comuneros de Segovia, mediante el informe favorable de la Gran Asamblea de Madrid.

La importancia de esta Merindad o Comunidad presidida por Abad en Valdepeñas es de primera magnitud, ya que conecta los acontecimientos de la provincia de Ciudad Real con la vida política nacional. Desgraciadamente Chaleco fue arrestado en noviembre y el 5 de diciembre fue

21 Resumen de la acusación existente en el Expediente Personal de Francisco Abad-Moreno Calvo. En dicho resumen está la correspondencia de la Merindad de Valdepeñas. 1822/23. Archivo Histórico Militar de Segovia. 
trasladado a la Real Cárcel de Valdepeñas ante su negativa a declarar. Como consecuencia de ello se le impuso "un par de grillos" y se le trasladó a la mencionada cárcel, donde el Juzgado quedó constituido para esta causa. Francisco Abad accedió a declarar negando todo lo que se le imputaba; el interrogatorio duró hasta el día 9 , fecha en que se le entregó a la jurisdicción real para ser juzgado de nuevo. Chaleco ese último día, y ante la resolución tomada de entregarlo a la justicia real, insultó a los jueces y al propio Capitán General de la provincia, presente en el interrogatorio.

Acusado de rebelde y conspirador Francisco Abad-Moreno, a sus 39 años, olvidados sus muchos servicios prestados a España en la Guerra de la Independencia, y víctima de la represión más dura de todas cuantas conoció el siglo xix, era condenado a morir decapitado en la ciudad de Granada el 21 de septiembre de 1827, y su cabeza era exhibida en un madero, para escarmiento público, "enfrente de la Bienbenida (Alcudia)" 22.

Tras su muerte dejaba Francisco Abad una España desolada, una viuda, Sacramento Muñoz, y cinco niñas en la miseria más absoluta, Maria y Francisca del primer matrimonio, con doce y trece años respectivamente, y María Juana, Ramona y Amalia del segundo, de diez, nueve y seis años. Años más tarde las hijas del primer matrimonio solicitarian la pensión de orfandad, como hija de militar rehabilitado, a la reina Isabel II en 1856. Debo destacar como nota curiosa que su segunda esposa,

22 Existen tres instancias que dirige la hija de Abad, Francisca, al Ministro de la Guerra en 1854, con el objeto de solicitar la Hoja de Servicios de su padre, con la finalidad de obtener pensión de orfandad, como hija de militar. La primera de ellas dice asi:

"Escmo. Sr. Ministro de la Guerra:

Don José Cejudo y Muñoz, considerando, con el Real despacho de Subteniente de Ejército por su instancia en la memorable época del año de 1820, con los distintivos de los alzamientos nacionales del 39,40 y este último, sargento segundo de la $1^{a}$ Compañía del $3^{\circ}$ Batallon de voluntarios nacionales de esta Corte; á V.E. con todo respeto espone: que enlazado con Doña María Francisca Abad y Frias, hija del malogrado Brigadier Coronel de Caballería Don Francisco Abad Moreno (a) Chaleco, decapitado en 21 de Setiembre de 1827 á manos del verdugo en la Ciudad de Granada por la ferocidad de los satélites del vandalismo, y separada su cabeza de los hombros, colgada encima de un madero enfrente de la Bienbenida (Alcudia), no ha podido conseguir Doña Sacramento Muñoz, última esposa de aquella víctima, la entrega de los documentos militares que á dicho su Padre Politico le pertenecian, con el justo fin de poner al corriente sus olvidadas vicisitudes, y servicios prestados al Trono reinante y Santa causa de la Libertad: para conseguirlo A V.E. rendidamente suplica que por un efecto de su notoria justificacion y civismo, se digne mandar se ponga literalmente copia de la hoja de vicisitudes de su Padre político Don Francisco Abad Moreno (a) Chaleco, como al propio tiempo y como tiempo y como duplicados los Reales Despachos de sus empleos y el de retiro, puesto que se los niega dicha Señora Madrastra de su citada esposa, y verificado ordenar le sean entregados á los fines que deja indicados: pues ademas de su justicia, impetra gracia de VE; cuya vida guarde Dios M. as. Madrid 9 de Setiembre de 1854. Rubricado José Cejudo Muñoz". Expediente personal y Hoja de Servicios de Francisco Abad-Moreno Calvo. Archivo Histórico Militar de Segovia. 
Sacramento Muñoz, se negó a facilitarle a María Abad la Hoja de Servicios de su padre, en virtud de la cual justificarian su petición de pensión, ya que la copia que había en el Archivo Histórico Militar de Segovia había desaparecido en un incendio años antes.

Perecía así, víctima de la reacción fernandina, al igual que otros muchos liberales españoles -Riego, Lacy, Mariana Pineda, etc-Francisco Abad-Moreno Calvo (a) Chaleco, para quien el único pecado había sido defender la patria en momentos difíciles, ante la invasión del ejército francés, y defender la libertad y el orden constitucional.

\section{BIBLIOGRAFIA}

Alcaldi Galiano, A.: Indole de la revolución en España de 1808, B.A.E., t. 84, Madrid, 1955.

Alcala Galiano, A.: Memorias, B.A.E., 1. 83, Madrid 1955.

ARTOLA, M.: “La guerra de guerrillas", Revista de Occidente, no 10, 1964, págs. 12 a 43.

AYMES, J.R.: "La gerrilla dans la lutte espagnole pour L'Independendance (1808-1814): amorce d'une théorique et avatars d'un practique". Bolletin Hispanique, 3-4, Juillet. 1976.

BARREdA Fontes, J.M; SÁnchez SÁnchez, I.: Contribución a la Historia de la prensa de la provincia de Ciudad Real, I.E.M., Ciudad Real, 1982.

Espoz y MinA, F.: Memorias, B.A.E., t. 146-147, Madrid, 1952.

FerRer Benimelul, J.A.: Bibliografía de la masoneria, Fundación Universitaria Española, Madrid, 1978.

FUENTE, V. DE LA: Historia de las Sociedades secretas antiguas y modernas en España y especialmente de la Francmasoneria, Imprenta Soto Freire, Lugo, 1870.

FrelRE López, A.M.: Indice bibliográfico de la colección documental de Fraile, S.H.M., Madrid, 1983.

Garcia Noblejas, J.A.: Manzanares. Guerra de la Independencia, Instituto de Estudios Manchegos, Madrid, 1982.

Gil Novales, S.A.: "Dias de persecución y terror (1814-1833)", Historia 16, extra III, junio, 1977.

Madfid Medina, A.: Valdepeñas, I.E.M., Ciudad Real, 1984.

Merlo Delgado, A.: "El Seis de Junio de 1808 en Valdepeñas", en Cuadernos de Valdepeñas (1). Guerra de la Independencia. Ed. Ayuntamiento de Valdepeñas, 1983, pás. 41 a 74.

MONESCILlo Diaz, M.A.; DEL VAlle, A.R.: "Valdepeñas durante la Guerra de la Independencia", conferencia pronunciada con motivo del bicentenario del nacimiento de Chaleco el 26 de mayo de 1988. En imprenta.

MONESCILLo DiAz, M.A.; DEL VALLE, A.R.: "Guerra y revolución liberal. 1808-1833", de próxima aparición en Historia de Ciudad Real, B.A.M.

MONESCILlo DIAZ, M.A.; DEL VALLE, A.R.: "La Guerra de la Independencia en Almagro" en Historia de Almagro, Ed. Diputación Provincial de Ciudad Real, 1988.

Vasco, E.: Guerra de la Independencia. Ocupación e incendio de Valdepeñas por las tropas francesas en 1808, Imprenta de Juan Mendoza, Valdepeñas, 1908.

VASCO, E.: Valdepeñeros ilustres. Apuntes biográficos, Valdepeñas, 1890-95.

Vasco Merlo, F.: Historia de Valdepeñas, Gráficas Cruz, 1959.

Zavala IRIS, M.: Masones, comuneros y carbonarios, Madrid, 1971.

\section{Fuente Documentales}

- Expediente Personal y Hoja de Servicios de D. Francisco Abad-Moreno Calvo. Archivo Histórico Militar de Segovia. Manuscrito. 
España entre el absolutismo y el liberalismo: Francisco Abad-Moreno Calvo,...

- Expediente Personal y Hoja de Servicios de D. Juan Toledo. A.H.M.S. Manuscrito.

- Expediente Personal y Hoja de Servicios de D. Juan Bacas. A.H.M.S. Manuscrito.

- Expediente Personal y Hoja de Servicios de D. Juan Navalón. A.H.M.S. Manuscrito.

- Expediente personal y Hoja de Servicios de D. Eugenio Sánchez. A.H.M.S. Manuscrito.

- Partida de Nacimiento de Francisco Abad-Moreno Calvo. Archivo de la parroquia de la Asunción de Valdepeñas.

\section{Fuentes Hemerográficas}

- El Zurriago, 1821-1856, Hemeroteca Municipal de Madrid. Biblioteca Nacional. Sección Manuscritos.

- El Eco de Padilla, 1821. Biblioteca Nacional. Sección Manuscritos.

- Gaceta de la Junta Superior de la Mancha. Elche de la Sierra. 1810-1813. Archivo Histórico Militar de Madrid.

- La Atalaya de la Mancha en Madrid. 1813. Archivo Histórico Militar de Madrid. 